\title{
Favela is painting. An UrbansparkZ/art installation of social commitment and organisational change
}

Favela é pintura. Uma UrbansparkZ/instalação de arte de compromisso social e mudança organizacional

Katarzyna Kosmala ${ }^{1}$

J. Miguel Imas ${ }^{2}$

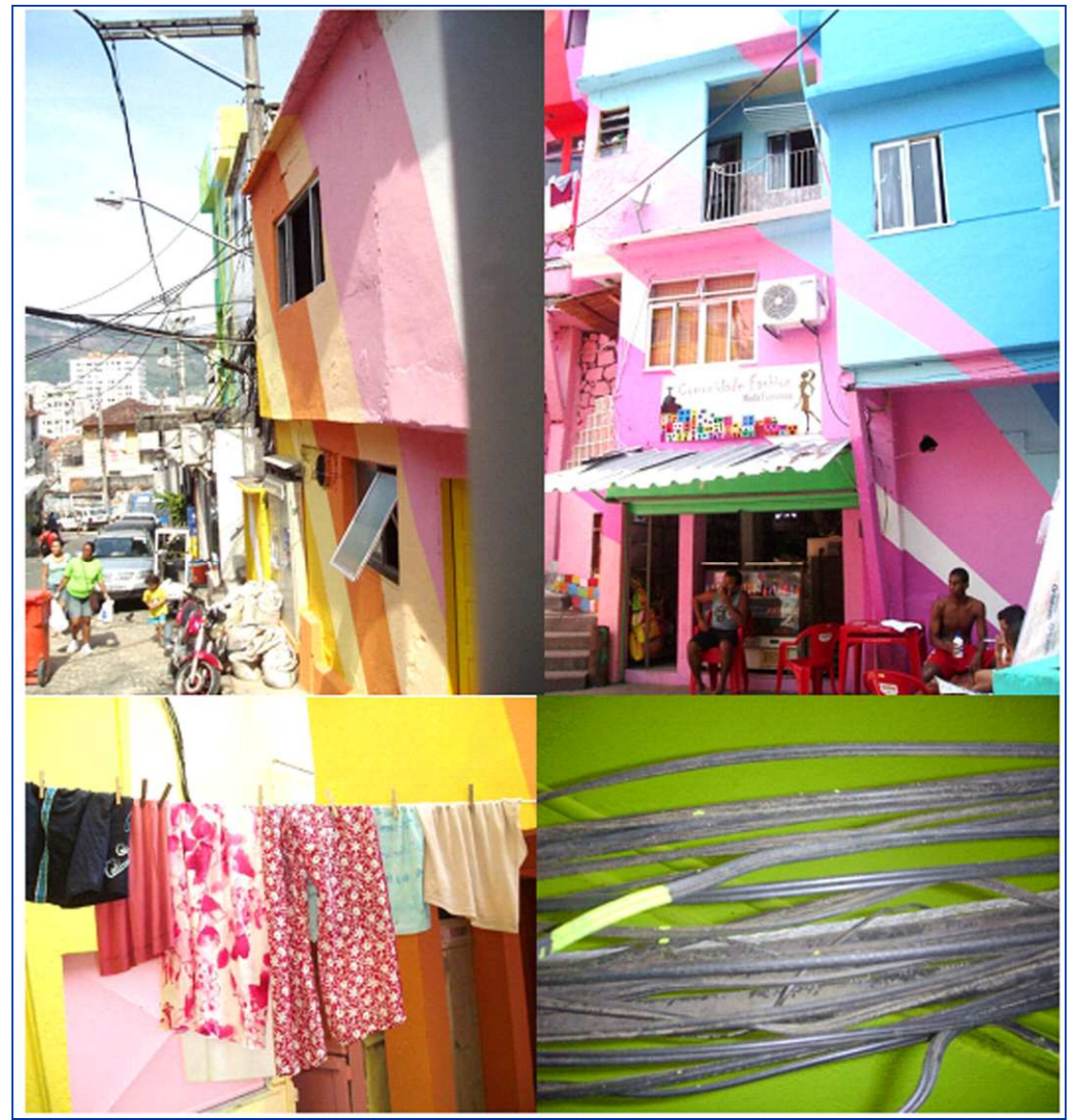

Source: Images 1-4 Favela Painting project Dona Marta, Rio de Janeiro, May 7, 2010. Photographs: Katarzyna Kosmala and Miguel Imas ${ }^{3}$

${ }^{1} \mathrm{PhD}$ MA(Hons) MSc. Professor in Culture, Media and Visual Practice. Faculty of Business \& Creative Industries. Address: University of the West of Scotland, UK. Email: katarzyna.kosmala@uws.ac.uk

$2 \mathrm{PhD}$ and BSc in Social Psychology (LSE). Senior lecturer in organisational-social psychology, creativity and change. Faculty of Business and Law, Kingston University. Address: Kingston University, Faculty of Business and Law, London, UK. Email: j.imas@kingston.ac.uk

${ }^{3}$ See JM Imas and K. Kosmala's letter on Dona Marta's Project, http://www.facebook.com/note.php?note id=125745827436274 (access, April 11, 2012). 
Brazil as emerging vibrant economy is a good example of a location where the urban context becomes a platform for research on sustainability issues, investigating the processes of modernisation and globalisation locally, in Latin America and more widely. Favelas are creative urban structures, neighbourhoods in which people strive to make a living despite poverty, and where violence is not denied but lived by. Appreciation of this contrasting representation reflects the work of Dre Urhahn (e.g., URHAHN URBAN DESIGN, 2010) and Jeroen Koolhas. Their Brazil-based projects involve painting façades of houses in these precarious urban spaces (see FAVELA PAINTING).

What can be described as an UrbansparkZ/Art installation, such work challenges stigmatised representation of periphery through the media spin that the project attracts, creating a different image altogether of the favelas communities. By Urbanspark $Z^{4}$ we suggest those activities which are neither formally managed nor organised within the corporate established aesthetic order, sparking meanings that celebrate alternative orders and disorders from music, graffiti to street performances; a true reflection of creativity; an artinstallation of social transformative consequences. As the installation is already somewhat appropriated by media discourse, it becomes a platform of social change, a platform that creates space for questions over established perceptions and assumptions of morro existence.

Indeed, media representation of what favelas are does not reflect imaginary potential of what these spaces truly are and, above all, the way in which people who inhabit them represent themselves, and by doing so, understand their own existence and environmental structures. Favelas, just like in Italo Calvino's novel (CALVINO, 2009) transform into invisible spaces, into invisible cities which are socially and economically excluded from the privileges of mainstream society. Favela dwellers however strive for a genuine improvement of living condition. With on-going pacification processes, they continue to co-exist in their invisible ways alongside mainstream society, in between the walls constructed on stigmatised perceptions.

'Favela painting' project based in Rio de Janeiro since 2006 through a collaborative effort and action by doing, affects the aesthetic order of how favelas are perceived from within and outside its natural embryonic growth. Colour brings hope. It brings a different understanding of space and its people, inviting others to cocreate and co-represent much more constructively and positively life here. It appeals to our senses in a way that we do not reject but embrace the potential for improvement living condition. The project articulates a different discourse of social change; of engagement, contributing to improve quality of life for favela dwellers. Like in the neighbourhood of Santa Marta where favelados in collaboration with Dre Urhahn and Jeroen Koolhas have 'intervened' and co-created a landscape of meaning at Praça Cantão that embraces a way out of being seen as part of a 'slum' but rather a creative cohesive community. Beyond the pure painting, the project opens the door to global networks via social platforms. The project engages with an imaginary community of activists, building spaces of engagement and virtual forums of like-minded individuals interested in change and participation in the socio-economic transformation of the precarious condition from the inside, collaborating in a new design for social/organisational co-existence in which favelas are integral part of community-driven action and not outcast spaces of invisibility. This is why the success of this project has far reaching consequences beyond the beaches and neighbourhoods of Rio de Janeiro and Brazil but to other informal spaces and urban voids in the world that are (lamentably) represented as unsustainable, violent and depreciated places in which to live and do work.

A work of art, as a finished object, as installation typically provokes a response based on the viewer's aesthetic experience. Yet, in Favela Painting projects discussed above, within a set of art relational practices (KESTER, 2004; 1999; BOURRIAUD, 1998/2002), it is an exchange of knowledge that forms an integral

${ }^{4}$ The notion of UrbansparkZ was developed by J. Miguel Imas in collaboration with Maria Daskalaki (Kingston University), Martyna Sliwa (Newcastle University) and George Cairns (RMIT). J. M. Imas coined the term inspired by the Dadaist movement and 'urban'[dis]order activities such as skateboarding, graffiti and parkour for an art of management and organisation conference stream in Poland 2006. 
part of the work itself. The focus is therefore on a process that challenges or shakes various stereotypes, fixed meanings, official discourses and media representation associated with what can be perceived and represented as 'precarious' places.

Grant Kester in his Conversation Pieces provides a definition of dialogical aesthetics as being 'based on the generation of a local consensual knowledge that is only provisionally binding and that is grounded at the level of collective interaction' (2004, p.112). Within a set of art practices that aspire to dialogic aesthetics, a reflective positioning can act as a catalyst for a change, potentially reviling more of the experiential specificity of the world through the context-focus unfolding. In a dialogic aesthetics frame, artistic practice embraces the importance of a dialogue, an integral component to an engaged practice, resulting in participatory process. Nicolas Bourriaud pointed out the way of working for some of contemporary artists today that are governed by a concern to 'give everyone their chance,' through forms which do not establish any precedence, a priori, of the producer [the artist] over the beholder, but rather negotiate open relationships with it (BOURRIAUD, 2002, p.58). Representational conventions of the arts and aesthetics, therefore, may be challenged by the creative facilitation of knowledge exchange and/or a possible dialogue formation and research. It is also a site-specificity that can become a space of encounter.

Dre Urhahn and Jeroen Koolhas' project epitomises an alternative creative way upon which to construct community in collaboration with local inhabitants. It brings more than hope, a true potential for sustainability and esteem that may prove significant in the fight against poverty, exclusion and depravation of favelados here in Rio de Janeiro and around the world. It breaks the poor image based on mediated stigmatisation of favelados, and as a result attracts other projects aimed at change, whether through better education or social and health necessities that can enrich already complex reality of local communities, with an attitude of pedagogy of hope (FREIRE, 1995). In such projects, based on collaboration with the local neighbourhood, where artist work alongside the 'pintores' in this social-art transformative drive, alters discourse and stigmatised favelas image for the good of the neighbourhood and the large community as a whole (KOSMALA, 2011).

Artists intervene in a particular locality, in a specific context and its spatiality ${ }^{5}$. Santos (2006, p.63) defines space as "an indivisible, integral and also contradictory set of systems of objects and systems of actions, not taken in isolation but as a unique scenario in which history unfolds". In this sense, each change arises from and generates new changes, because "the spatial forms also oblige other social structures to transform themselves, striving for adaptation, whenever they cannot create new forms" (SANTOS, 2008, p.45). Critical and resisting potential in such method of working acquires a more pragmatic form. Artists seem concerned with the specific effects produced by exchanges of communication in a given milieu. An inquiry also embraces a movement and expands into virtual spaces. Art practice becomes performative medium, creating a platform for a discussion on change, engagement with a social reality through the multiple registers of meanings. In other words, it is by participating and re-writing the politics of everyday life, this very process becomes the art practice.

\section{References}

BOURRIAUD, N. Relational Aesthetics. Les Presses du Reel, 1998/2002.

CALVINO, I. Invisible Cities (new ed.). Vintage Classics 2009.

${ }^{5}$ As Bourriaud explains in Relational aesthetics art is the place that produces a specific sociability (1998/2002, p.16), it is a state of encounter. The artistic process also involves mapping and documenting of what happens. Multiple registers of meanings are results of such practice. 
FAVELA PAINTING. http://www.favelapainting.com/. Access April 11, 2012.

FREIRE, P. Pedagogy of Hope: Reliving Pedagogy of the Oppressed. New York: Continuum, 1995.

KESTER, G. Dialogical Aesthetics: A Critical Framework for Littoral Art. Variant, Issue 9, Winter, 1999. 2004. Conversation Pieces: Community, Communication in Modern Art. Cal: University of California Press,

KOSMALA, K. Temporality and Alteration of Social Boundaries in the Making of an Art Installation. Creative Industries Journal, v. 4, n.1, p. 53-69, 2011.

SANTOS, M. A Natureza do Espaço: Técnica e Tempo. Razão e Emoção. São Paulo: Editora da Universidade de São Paulo, 2006.

Da Totalidade ao Lugar. São Paulo: Editora da Universidade de São Paulo, 2008.

URHAHN URBAN DESIGN. The Spontaneous City. Amsterdam: Blis Publishers, 2010. 